\title{
CONVERSION OF FUSED HIPS TO LOW FRICTION ARTHROPLASTY
}

\author{
Kevin Hardinge, Wigan, England, Desmond Williams, Perth, Western Australia, \\ André Etienne, Nice, France, Donald MacKenzie, Pretoria, South Africa, \\ and John Charnley, Wigan, England
}

\begin{abstract}
Fifty-four hips converted to low friction arthroplasty between 1965 and 1975 have been reviewed one to eleven years after operation. In many cases malposition had led to degenerative changes in the opposite hip, the lumbar spine or the knee, often with severe loss of function due to pain. It was found that total replacement could give useful relief of pain and improved function, though the range of movement obtained was not as good as in primary replacement. An outstanding feature was the correction of inequality of leg length. In general, the results were much better in cases of ankylosis acquired in adult life than in cases of spontaneous fusion after sepsis in childhood. The most important complication was a single case of sciatic palsy.
\end{abstract}

In the decade January 1965-75, fifty-four hips with bony or firm fibrous ankylosis were treated by total replacement at Wrightington Hospital. This represents 0.6 per cent of the 9,208 low friction arthroplasties performed in the same period. Cases of fusion (whether spontaneous or surgical) in ankylosing spondylitis and rheumatoid arthritis have been excluded from this series; an experience of their surgical treatment has been reported elsewhere (Welch and Charnley 1970).

\section{CLINICAL MATERIAL}

There were fifty-two patients; in two both hips were converted, making a total of fifty-four hips. Thirty-five patients were women and seventeen were men. The right hip was converted in thirty-four instances and the left in twenty. For convenience in this paper, and because there were only two bilateral cases, patients will be referred to by the disorder of the hip that led to their disability.

TABLE I

The Earlier Pathology of the Fifty-four Hips

\begin{tabular}{|l|c|c|c|}
\hline \multicolumn{1}{|c|}{ Pathology } & \multirow{2}{*}{$\begin{array}{c}\text { Number of } \\
\text { hips }\end{array}$} & Spontaneous & Surgical \\
\cline { 3 - 4 } & 17 & 12 & 5 \\
\hline Tuberculous or pyogenic arthritis & 2 & - & 2 \\
Congenital dislocation & 6 & 1 & 5 \\
Trauma & 29 & 1 & 28 \\
Osteoarthritis & & & \\
\hline
\end{tabular}

This study is a general review of hips once ankylosed for other reasons; they were either clinically and radiologically soundly fused, or had at most a few degrees of flexion movement, before being converted to low friction arthroplasties. It emphasises the indications for arthroplasty, important aspects of technique, and the factors that influence the final results.
There were two main groups of cases: the infections of childhood and degenerative osteoarthritis (Table I). In the infective group, of ten hips that had fused spontaneously following tuberculosis, three showed old healed sinuses. All specimens taken routinely at operation gave negative cultures. In the osteoarthritis group six recent fractures had occurred adjacent to the

Kevin Hardinge, M.Ch.Orth., F.R.C.S., Centre for Hip Surgery, Wrightington Hospital, Appley Bridge, Wigan, Lancashire WN6 9EP, England.

Desmond Williams, B.Sc., F.R.A.C.S., Department of Orthopaedic Surgery, Royal Perth Hospital, Western Australia.

Dr André Etienne, Service des Urgences, Hôpital St Roche, Nice (06), France.

Dr Donald MacKenzie, M.Med., F.R.C.S., Pasteur Building, Schoemann Street, Pretoria 0002, South Africa.

Sir John Charnley, C.B.E., F.R.S., F.R.C.S., D.Sc., Centre for Hip Surgery, Wrightington Hospital, Appley Bridge, Wigan, Lancashire WN6 9EP, England. 


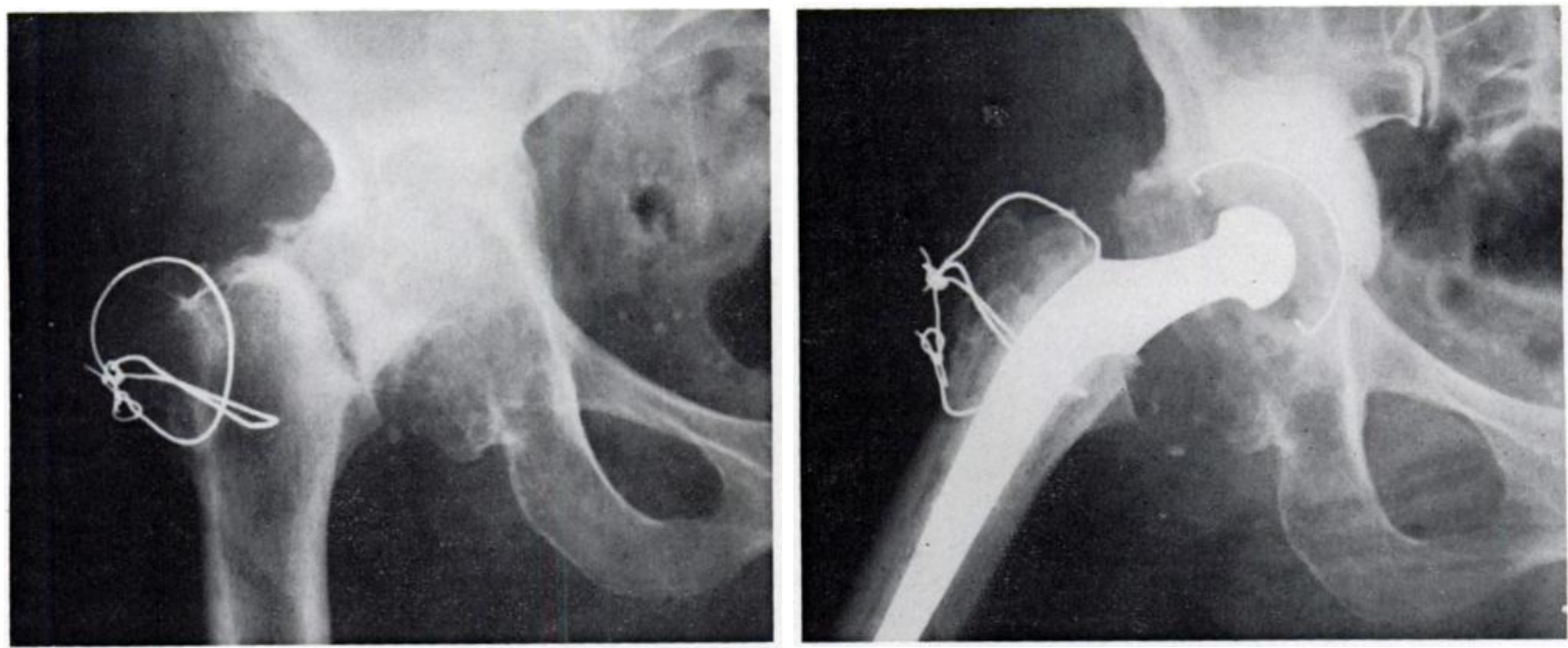

Fig. 1

(Left-hand side) A radiograph of a case of central displacement stabilisation with sound ankylosis in which a fall onto the greater trochanter caused a fracture of the neck of the femur. (Right-hand side) The same case after conversion of the hip to a low friction arthroplasty.
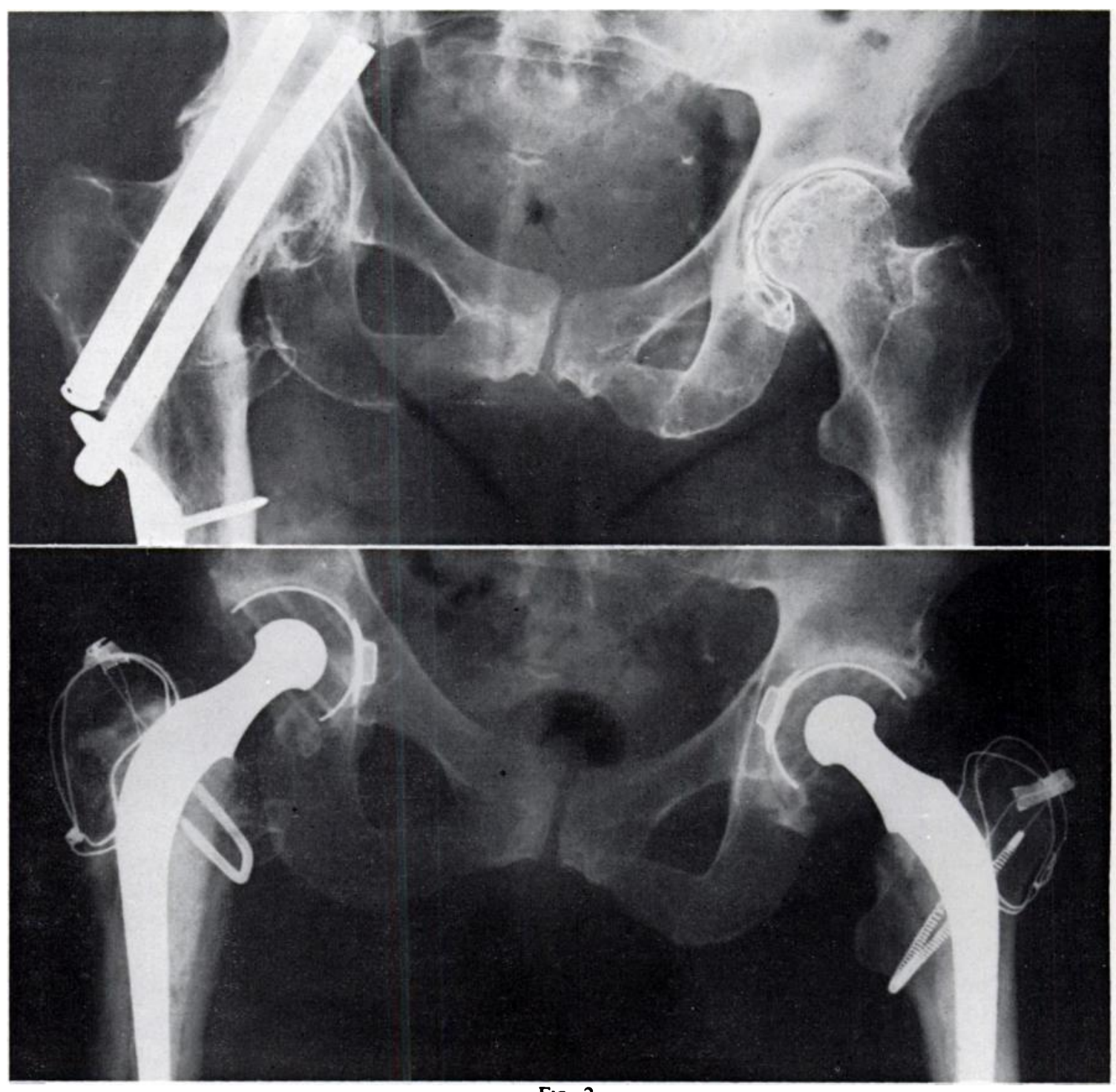

Fig. 2

(Above) A radiograph of a case of attempted fusion of an osteoarthritic hip using a pin and plate and a separate tri-fin nail. The joint space was still present and a trace of movement could be detected. The left hip also shows osteoarthritis. (Below) The same hips after conversion to low friction arthroplasties. 

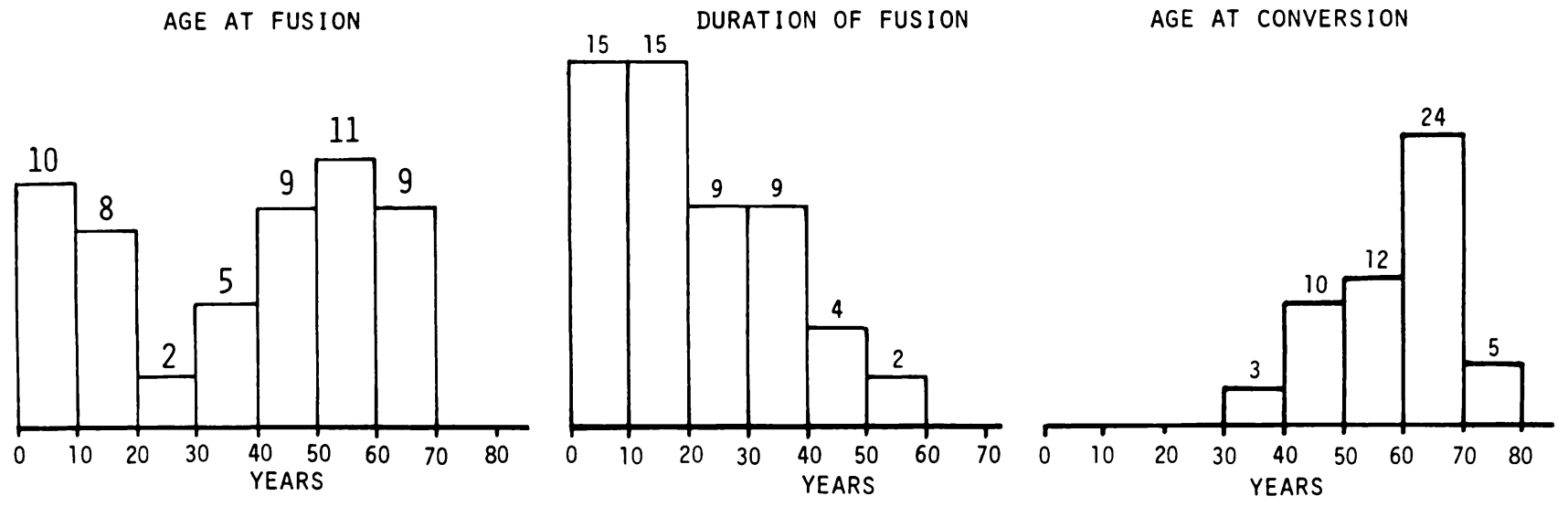

Fig. 3

A diagram to indicate various details of the fifty-four hips.

ankylosed hip - one from a fall causing a fracture above the spline used for internal fixation, one from a road traffic accident and four from falls in cases fused by the central displacement procedure (Fig. 1).

In thirty-eight hips no movement could be detected clinically. The other sixteen hips had detectable flexion movement - six from an adjacent fracture and ten that showed either radiolucency around metal implants or firm fibrous union after attempted surgical fusion (Fig. 2). Of the ten unsound fusions just mentioned, four followed attempted intra-articular fusion with metal fixation and six followed central displacement stabilisation. The latter procedure was originally devised to reduce movement in painful arthritic hips; thus it could be expected to produce an "unsound" fusion, but in this series it had also given nine cases of sound bony union.

The age at the time of ankylosis ranged from five to sixty-eight years, the average being thirty-eight years (Fig. 3). The duration of ankylosis ranged from two to fifty-eight years, the average being twenty-one years. The age at arthroplasty ranged from thirty-two to seventy-four years, the average being fifty-nine years. The period of follow-up ranged from one to eleven years, the average being two and a half years.

\section{Indications for conversion}

An unsound fusion with local pain and instability is a ready indication, but this cannot apply to a hip soundly fused. In the latter group of patients the indication arose from degenerative osteoarthritis in adjacent joints caused by malposition. The patients with fusions of childhood often managed for thirty years before decompensation set in with the development of secondary osteoarthritis. Many of the women had brought up a family but had noticed increasing disability in the fifth decade until eventually they became severely crippled (Fig. 4). Other patients complained of inability to perform a specific function such as sitting or driving. Thus an engineering bench assembler could no longer sit for long periods because of increasing low backache and was in danger of losing his job.

Two patterns of deformity were observedabduction, flexion and lateral rotation in the one, and adduction, flexion and medial rotation in the other. The hips in the most severe malposition were those in abduction; moderate abduction was seen to produce lumbosacral degeneration, whereas severe abduction

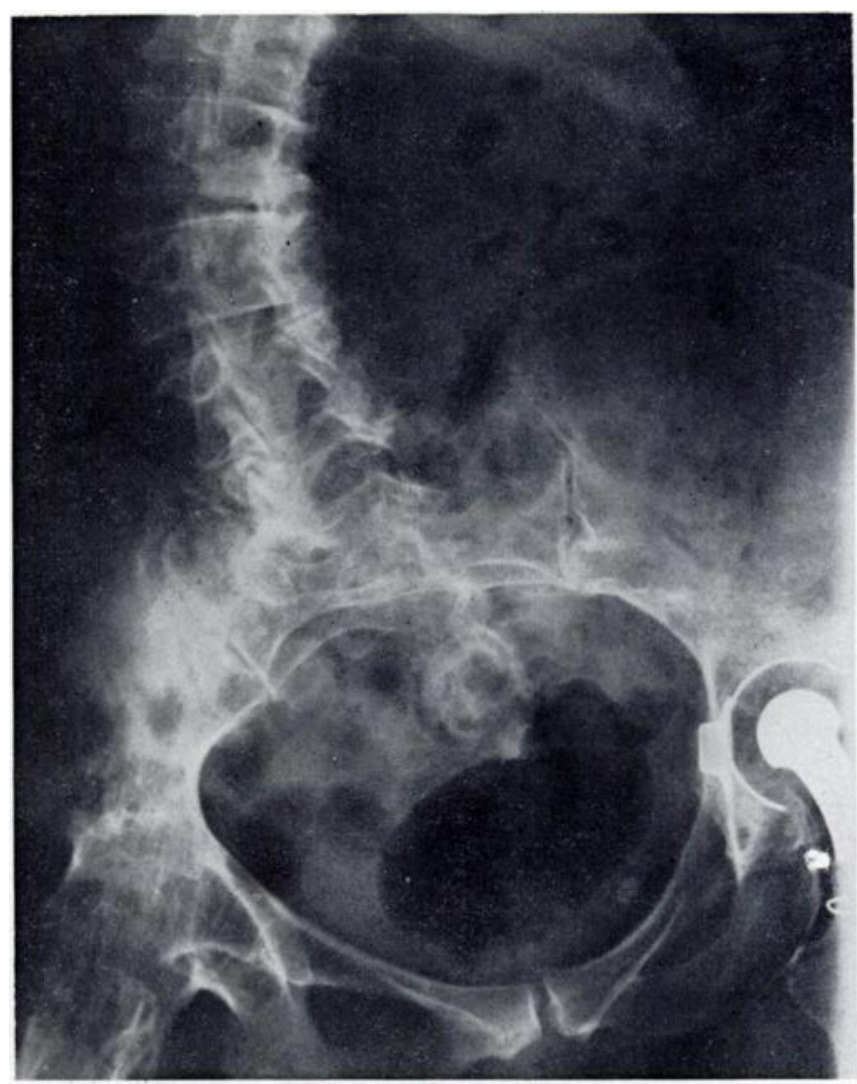

Fig. 4

A case of tuberculosis of the right hip in childhood with spontaneous fusion in abduction leading to secondary scoliosis and an adduction deformity of the left hip with osteoarthritis. After bilateral replacement the function of walking improved from .a chair-bound state to ability to walk three miles, and the low back pain was much reduced. 
would also cause degeneration of the opposite hip (Fig. 5). A hip fused in adduction and medial rotation was usually associated with instability and degeneration of the ipsilateral knee, presumably because the patient could not lock it in extension.

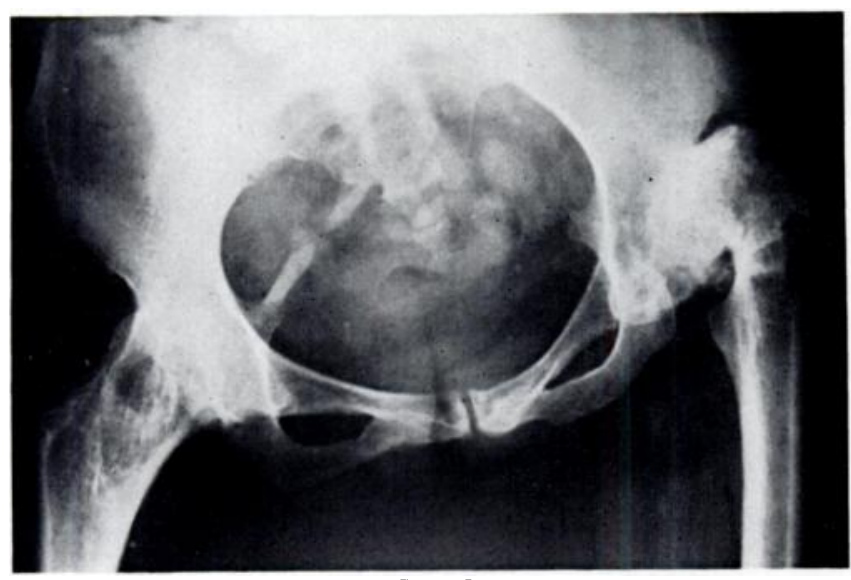

FiG. 5

A case of sepsis of the right hip in infancy, with spontaneous fusion in abduction leading to adduction of the left hip and degenerative osteoarthritis. Note the suppression of the right greater trochanter.

In the case of a severely deformed hip it was unusual to find a single complaint; major disability was often caused by a compounding of reduced exercise tolerance in middle age as a result of cardiorespiratory decompensation together with severe degenerative changes in the associated joints. The patients with particularly severe disability were those with a hip fused on one side-mainly for osteoarthritis-and now with degenerative osteoarthritis on the other.

At the time of review in this series, a total hip replacement was present on the side opposite the once fused side in twenty-two patients, fifteen having been performed before the conversion and seven afterwards.

\section{SURGICAL TECHNIQUE}

Before the actual operation clinical and radiological assessment help to determine the amount of shortening present, the deformity, the position of the fusion (high or low in relation to the old acetabulum), the presence or otherwise of a joint space in cases of incomplete fusion, and the size and disposition of the greater trochanter. If the hip is in neutral rotation the trochanter as a rule is easily palpable and is visible radiologically; in these patients it is possible to test for abductor power and to predict the probable range of abduction after surgery. If the hip is fused in a rotated position, however, it is not usually possible to test for abductor power and it may be difficult to estimate the size of the trochanter.

The lateral approach to the hip joint, with reflection of the greater trochanter and reattachment at the end of the arthroplasty, has been routine in this Unit. It has been observed that good power of abduction is readily regained after such reattachment, which is attributed to the avoidance of damage by stretching or strong retraction of gluteus medius. Trochanteric detachment in the supine position allows a complete circumferential view of the acetabular region - vital for the success and safety of these conversions.

The hip joint is approached by the standard lateral incision with the greater trochanter at its mid-point. The trochanter is exposed and its size and the state of gluteus medius are noted. A good size of trochanter is important for achieving a sound reattachment. Routine separation of the trochanter is usually by Gigli's saw, but if it is poorly formed an oscillating saw is used to fashion a larger fragment from the outer aspect of the region. If the trochanter is well formed there is usually a wellformed gluteus muscle, but in old cases of infantile sepsis there may be atrophy of both.

The trochanter is carefully mobilised further to relax the gluteus medius and the anterior and posterior borders of the acetabulum are defined with Hohmann's retractors. A common feature is the insertion of the remains of the superior capsule into the upper lip of the old acetabulum; these are retracted with pins so that the region is clearly defined in its circumference.

The neck is now divided by an oscillating saw. Both the level and the inclination of section are determined by inspection of the radiographs. It is important to gain as much length as possible so as to impose stretching of the capsular and ligamentous structures around the hip, to give a tight reduction, and to restore leg length as necessary. If the fused hip is in a "high" position and there is loss of length, a high section of the neck will gain length and ensure a tight reduction (Fig. 6).

Of great importance is the inclination of the section. If there is a flexion deformity the neck is divided higher in front than behind, so that when the flexion deformity is
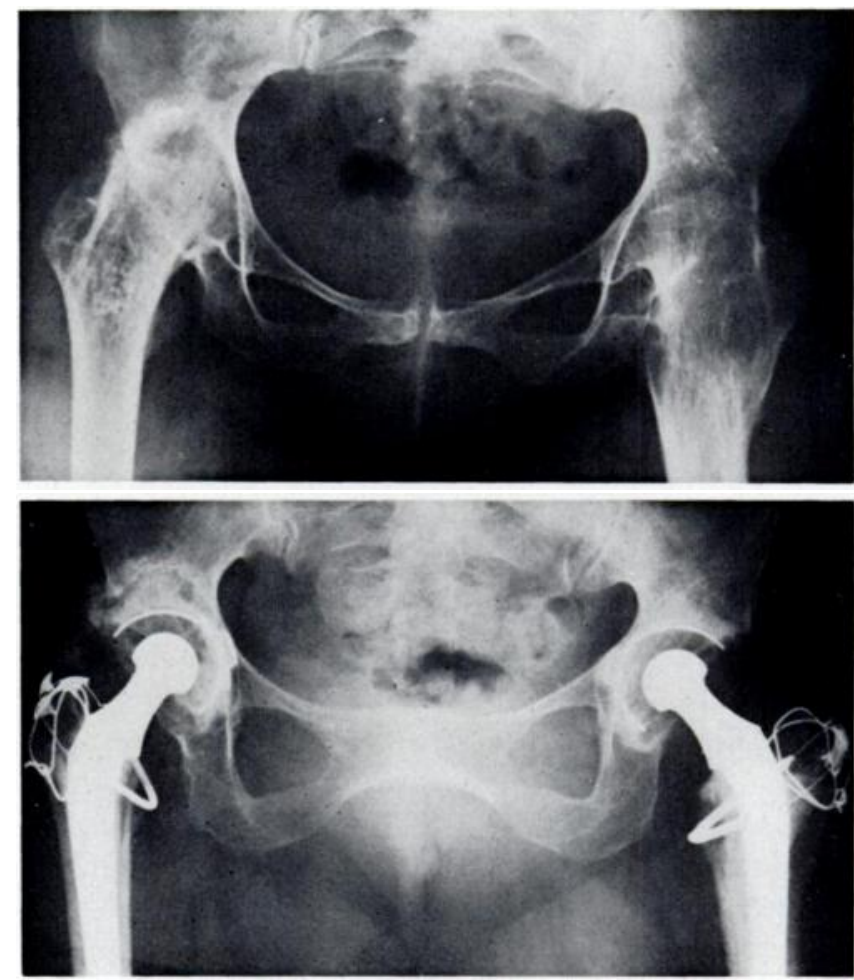

Fig. 6

(Above) The radiograph of a case of bilateral spontaneous fusion of the hip after tuberculosis in infancy. The more extensive destruction of the right acetabulum has led to a higher position of the fusion. (Below) The same case after bilateral arthroplasty. The low position of the cup on the right side has favoured the equalisation of leg lengths. 


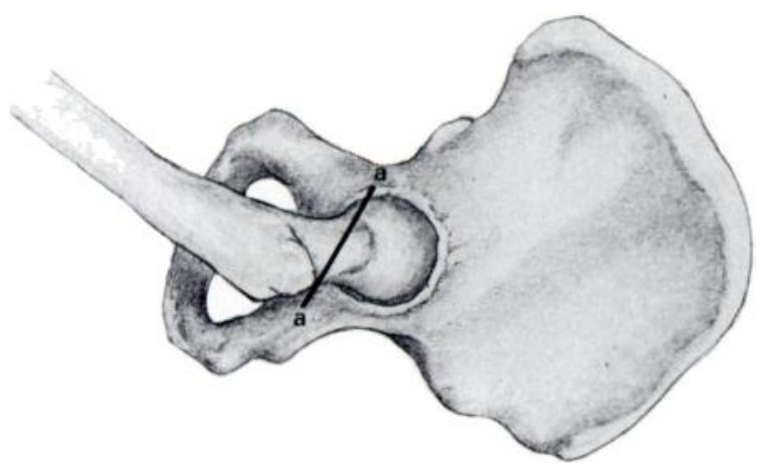

released, the line of section of the femoral neck is perpendicular to the axis of the femur (Fig. $7 \mathrm{a}-\mathrm{a}$ ).

In cases of long-standing fusion from childhood sepsis, anteversion of the neck may have been retained. This, even in the presence of a minimal flexion deformity, similarly demands an inclined section of the femoral neck but now from low anterior to high posterior (Fig. $7 \mathrm{~b}-\mathrm{b}$ ).

When the neck has been divided, mobilisation of the femur is often aided by division of the psoas tendon; the thigh is then adducted across the mid-line so as to expose the stump of the neck and the fused head in the acetabulum. By reference to the radiograph the level of the reaming for the cup is gauged with accuracy. It is standard practice in this Unit to seek a low placement of the cup; this allows a tight reduction, which is a safeguard against dislocation. The

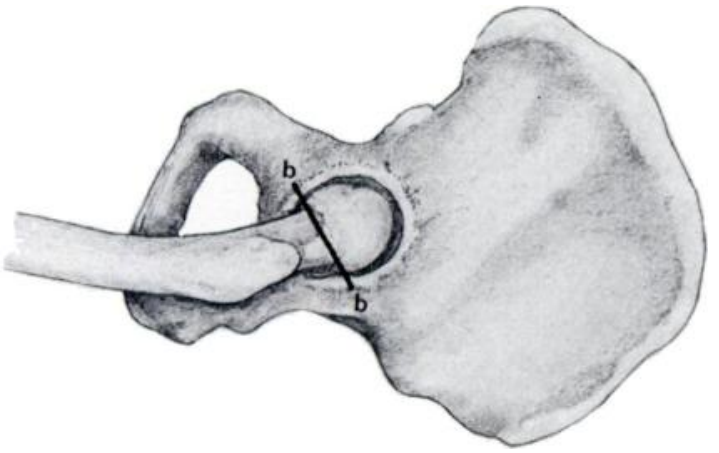

FIG. 7

(Above) Disposition of the femoral neck and acetabulum in fusion with flexion deformity. Line of section-high anteriorly, low posteriorly-ensures that section is at right angles to the shaft when the flexion deformity is released. (Below) Persistent anteversion of femoral neck in infantile sepsis. Level of section needs to be inclined low anteriorly to high posteriorly to obtain perpendicular end face of the neck of femur. deepening is started with gouges and progresses with the deepening reamer so as to obtain full bony cover for the socket. When a joint line still shows on the radiograph, or when a fibrous ankylosis is suspected, it is important to reach the original acetabular floor and remove all remnants of cartilage. Failure to do so is a potential source of loosening at a later date. With this surgical approach the reaming of the acetabulum becomes a fairly straightforward procedure and the remainder of the operation follows the normal routine.

After-care - The period of immobilisation depends on the consistency and fixation of the trochanter. If the trochanter has been found to be normal with a good gluteus medius (Fig. 8 ), the common practice is to splint in abduction for up to seven days but to allow walking two days after operation. If the trochanter is poor and gluteus medius thin, the splintage in abduction is prolonged for two to three weeks to prevent disruption of the abductors. Even thin strap-like abductors have regained useful power over the two years after operation.
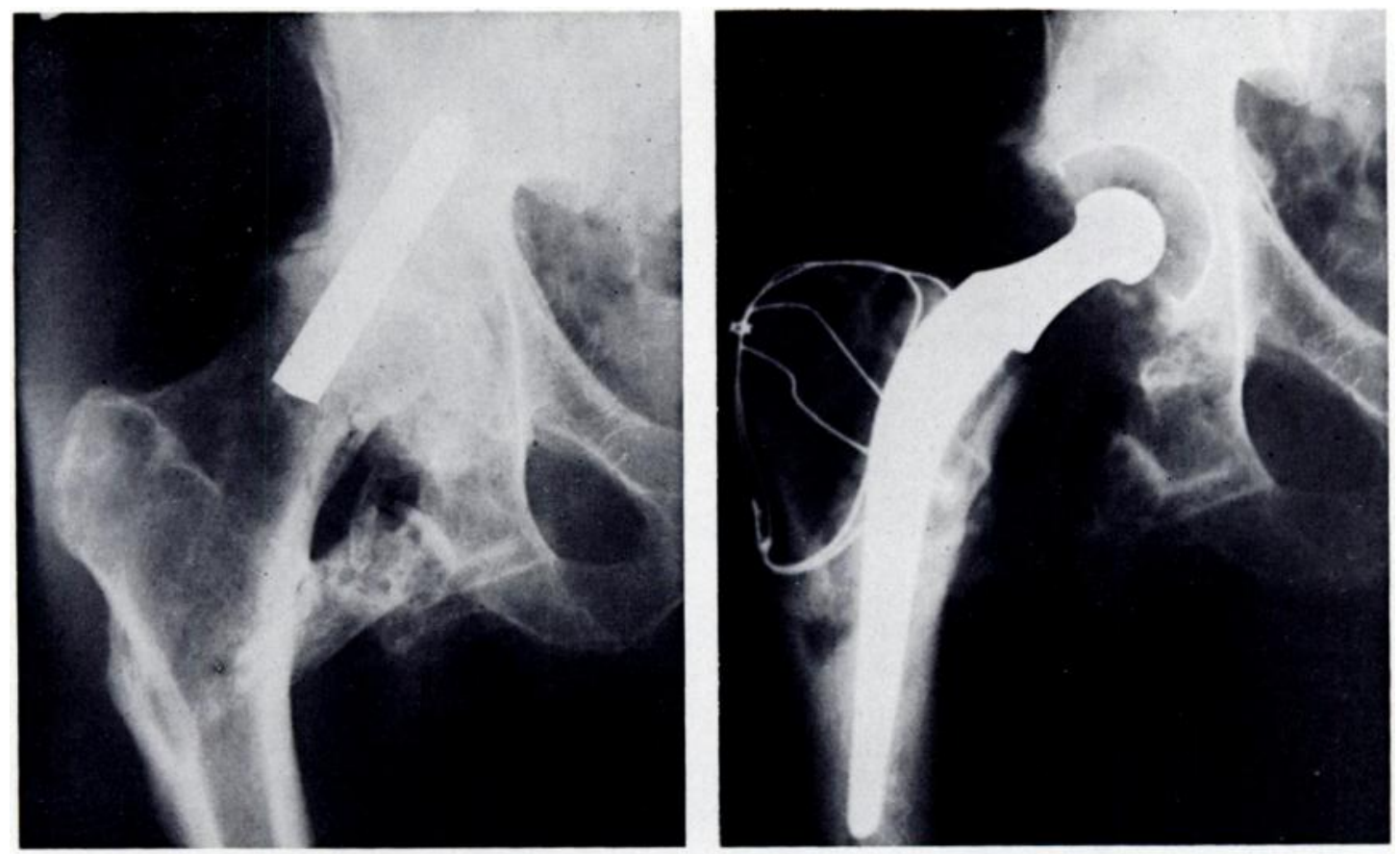

Fig. 8

(Left-hand side) A radiograph of a case of osteoarthritis of the hip for which fusion was attempted by means of an ischio-femoral graft and a transarticular tri-fin nail. The nail fractured and part was removed. The "fusion" became painful on weight-bearing, and a joint line persisted. (Right-hand side) The same hip after canversion to low friction arthroplasty. 


\section{RESULTS}

Early complications-Deep vein thrombosis occurred in one case and three cases of pulmonary embolus presented as transient episodes of pleuritic pain. Anticoagulants were not prescribed and all four patients made a satisfactory recovery on symptomatic treatment. There were no dislocations in this series. In one case early superficial infection presented as a haematoma which drained spontaneously on the eighth day; cultures showed Staphylococcus aureus and the infection settled rapidly with a course of cloxacillin. Detachment of the greater trochanter occurred in two cases; both were reattached with satisfactory results. Sciatic nerve palsy occurred in one case.

Her troubles began at the age of six with tuberculosis of the right hip which led to many sinuses and spontaneous fusion. At the age of fifty she presented with the hip fixed in abduction, marked secondary degenerative changes of the left hip and low back pain. Arthroplasty was performed, first on the left hip and a month later on the fused right hip. This was a difficult procedure because of fibrosis around the upper end of the femur and absence of the greater trochanter. Mobilisation of the femur was exceptionally difficult; it required the division of dense adhesions and considerable stretching of the soft tissues. A complete sciatic nerve palsy was noted on her return to the recovery room. A month later the sciatic nerve was explored through a posterior incision lateral to a healed sinus track, and found in dense fibrous tissue bound down to the posterior surface of the femur at the level of the joint. The nerve was freed, but this led to only partial recovery and the patient needs to wear a below-knee caliper.

Late complications - Deep sepsis is suspected in one case. This patient has pain at night in the thigh but the erythrocyte sedimentation rate has never been raised. A cyst is developing in the acetabulum and the patient is being followed up with a view to removal of the prosthesis if symptoms worsen. New bone formation limited movement in three cases, but only in one did it cause a poor overall grading. There were two other cases with poor results, one being the case of sciatic palsy already mentioned.

The last patient complains of insecurity of the hip and has a poor gait. During the conversion it proved impossible to raise the trochanter; the abductors had to be shingled away from the bone and sutured back later. The patient has not regained any active abduction, which contributes to her poor gait.

\section{The numerical grading of hips}

Grading the quality of a hip joint by a numerical code provides a means of comparing the state before and after operation. The method used in this Unit (Fig. 9) follows that of Merle d'Aubigné and Postel (1954) which grades the hip by three sets of numbers ranging from 1 to 6 , pain being represented by the first number, walking function by the second and the total range of movement by the third. The figure 6 represents normality.

The addition of decimal figures helps to indicate the predominant grading within a group. Thus if the result for a group is given as $4 \cdot 75$, this could indicate that 75 per cent of the group were graded 5 and the remainder 4 . In this way a fairly accurate impression of the general state of affairs can be rapidly gained.

\begin{tabular}{|c|c|c|c|c|c|c|}
\hline $\begin{array}{l}\text { NUMERICAL } \\
\text { GRADING }\end{array}$ & 1 & 2 & 3 & 4 & 5 & 6 \\
\hline PAIN & $\begin{array}{l}\text { Severe } \\
\text { Fraciure pain }\end{array}$ & $\begin{array}{l}\text { Severe } \\
\text { Activily } \\
\text { olmost } \\
\text { prevented }\end{array}$ & $\begin{array}{l}\text { Spont. poin } \\
\text { Night poin } \\
\text { Sposm }\end{array}$ & $\begin{array}{l}\text { Activity } \\
\text { poin }\end{array}$ & $\begin{array}{l}\text { Slight } \\
\text { Intermittent }\end{array}$ & No poin \\
\hline $\begin{array}{l}\text { FUNCTION } \\
\text { OF } \\
\text { WALKING }\end{array}$ & Bedridden & $\begin{array}{l}\text { Very limited } \\
\text { House-bound }\end{array}$ & $\begin{array}{l}\text { Limited } \\
\text { Wolks } \\
<1 \text { mile or } \\
<1 \text { hour } \\
\text { Stick always }\end{array}$ & $\begin{array}{l}\text { Wolks } \\
>1 \text { mile or } \\
>1 \text { hour } \\
\text { Stick support }\end{array}$ & $\begin{array}{l}\text { Minor limp } \\
\text { No stick }\end{array}$ & $\begin{array}{l}\text { Normal } \\
\text { for age }\end{array}$ \\
\hline $\begin{array}{l}\text { TOIAL } \\
\text { RANGE OF } \\
\text { MOIION }\end{array}$ & $0-30^{\circ}$ & $-60^{\circ}$ & $-100^{\circ}$ & $-160^{\circ}$ & $-210^{\circ}$ & $-260^{\circ}$ \\
\hline
\end{tabular}

FiG. 9

Numerical grading of hips (after Merle d'Aubigné and Postel 1954).

Pain, function and movement - The average gradings of the fifty-four hips before arthroplasty and at six months, twelve months and final review are shown in Table II. Pain-At twelve months pain was graded at 6 (no pain) in forty-two hips and at 5 (slight or intermittent pain) in eleven hips; in only one case was the grade less than this. The pattern improved from an average of 4.6 before operation to 5.8 at six months, and to 5.9 at final review.

\section{TABLE II}

The Average Numerical. Gradings of the Fifty-four Hips Before and After Low Friction Arthroplasty

\begin{tabular}{|l|c|c|c|}
\hline & Pain & Function & Movement \\
\hline Before operation & 4.6 & 3.3 & 1.0 \\
After operation & & & \\
At six months & 5.8 & 3.8 & 3.9 \\
At twelve months & 5.7 & 4.5 & 4.3 \\
At review & 5.9 & 5.0 & 4.7 \\
\hline
\end{tabular}

Function-By twelve months there had been a shift from overall limited walking ability (grade 3.3 ) towards substantially free general mobility (grade $4 \cdot 5$ ). Eleven patients now had a grade of 6 , seventeen a grade of 5 and sixteen a grade of 4 . In other words, these forty-four patients could walk either normally or with a minor limp, or at worst could manage long distances with the aid of a stick. At review the overall grading had improved to 5.0. Significant improvement in the ability to walk was usually accompanied by a corresponding improvement in gait.

Movement-All the hips were of course grade 1 before arthroplasty. Table II emphasises the dramatic change twelve months after operation - all except six hips had a 
total range of passive movement in all directions of over 100 degrees. The usual pattern was one of initial rapid gain up to six months, continued improvement till twelve months, and then a more gradual increase up to the time of final assessment.

When the range of movement was examined in three different groups (Table III), it was found that the gain in hips fused at a younger age was less than that achieved in hips fused in adult life. The least gain was in cases of spontaneous fusion after infection.

The influence of malposition of the fusion on the range of movement was examined in two extreme groups. It was found that the range of movement in the direction opposite the deformity was poor at six months, whereas at twelve months it was neutral. As for abduction in general, after arthroplasty the average range of active movement was 18 degrees and of passive movement 27 degrees, the difference reflecting lack of abductor power.

\section{DISCUSSION}

The decision for total replacement of a fused hip can be justified if the limb is in a deformed position causing degenerative changes in other joints. Many of the hips in this series were in severe malposition, worst in the cases of sepsis in childhood. As children, most of these patients had endured long periods of immobilisation, either on a Robert Jones frame or in a plaster spica or both. If the period had been prolonged in the hope of fusion, it was always difficult at that time to determine if and when the joint had soundly fused. Some of these patients must have had progressive deformity after release from the immobilisation before fusion became complete.

It was found that if a hip once infected had been ankylosed for upwards of ten years with complete bony cross-trabeculation there was no danger of reactivation; specimens for culture taken routinely at operation never showed any growth.

TABLE III

A Comparison of the Average Resulits in Different Age Grol ps

\begin{tabular}{|c|c|c|c|c|c|}
\hline & $\begin{array}{l}\text { Average age } \\
\text { at fusion } \\
\text { (years) }\end{array}$ & $\begin{array}{c}\text { Average } \\
\text { duration } \\
\text { of fusion } \\
\text { (years) }\end{array}$ & Pain & Function & Movement \\
\hline Fusion after the age of twenty ( 36 hips) & 51 & $13 \cdot 0$ & $5 \cdot 6$ & 4.4 & $4 \cdot 3$ \\
\hline All fusions before the age of twenty ( 18 hips) & 12 & 38.0 & $5 \cdot 9$ & $4 \cdot 7$ & $4 \cdot 0$ \\
\hline Spontaneous fusion before the age of twenty ( 11 hips) & 10 & $38 \cdot 5$ & 5.9 & 4.9 & $3 \cdot 6$ \\
\hline
\end{tabular}

Leg length - Before operation forty limbs on the side of fusion were short by an average of 3.5 centimetres (nine by 5 centimetres or more); ten were about equal; and four were long by an average of 3.5 centimetres, the most being 5 centimetres. After arthroplasty an outstanding feature was the correction of inequality. Twenty-six were short by an average of 1 centimetre, twenty-six were almost equal, and in two there was lengthening of 2 centimetres.

Back and knee symptoms - In eighteen patients backache had been a contributory indication for conversion; only four had residual pain. In some patients, despite advanced radiological changes in the lumbosacral spine, the relief allowed a considerable improvement in walking even though pain was still a restraining factor. Thus one patient previously chairbound became able to walk three to four miles, albeit with the support of one stick; her backache, though greatly reduced, was still the limiting factor. This confirms the findings of Brewster, Coventry and Johnson (1975).

Complaint of the knee was an indication for conversion in twelve patients but still limited walking in eight of them.
The poorest range of movement after conversion was regained in those cases with most years of fusion (Amstutz and Sakai 1975), but even more important was the age of onset of the disease leading to it. Much the poorest range was found in old cases of infantile sepsis; all these had depression of growth of the upper end of the femur, giving a direct effect upon the size of the trochanter and the related musculature (Fig. 8).

The technique of low friction arthroplasty with trochanteric detachment is seen to be a safe procedure that allows accurate siting of the acetabular component, thus presenting an opportunity to equalise leg length. Of course there is an upper limit to the amount of true shortening that can be corrected by any method of total replacement because too great a stretching of the soft tissue can either prevent reduction or damage the sciatic nerve. The greatest discrepancies occurred in the infantile infection group as a result of combined true and apparent shortening. It was rare for the true shortening to exceed 4 centimetres, which is the upper limit of lengthening by the present technique, but the restoration of true length coupled with reduction of deformity gave a high measure of equalisation. 
The final strength of abduction can approximately Many patients with severe backache before conversion be predicted from the original disease process. In are emphatic as to the relief of symptoms. Degenerative general it is poor after infantile sepsis, giving an lumbosacral spines show a gratifying ability to comabnormal pattern of gait, but good after fusion in maturity from non-infective causes. pensate when so relieved. Pain in the knee is not so markedly relieved by conversion; this probably

If malposition causes strain on associated joints, stems from the position and anatomical nature of the conversion to a neutral position relieves that strain. joint.

\section{REFERENCES}

Amstutz, H. C., and Sakai, D. N. (1975) Total joint replacement for ankylosed hips. Journal of Bone and Joint Surgerv, 57-A, 619-625.

Breuster, R. C.. Coventry, M. B.. and Johnson, E. W., Jun. (1975) Conversion of the arthrodesed hip to a total hip arthroplasty. Journal of Bone and Joint Surgery, 57-A, 27-30.

Merle d'Aubigné, R., and Postel, M. (1954) Functional results of hip arthroplasty with acrylic prosthesis. Journal of Bone and Joint Surgery, $36-A, 451-476$.

Welch, R. B., and Charnley, J. (1970) Low-friction arthroplasty of the hip in rheumatoid arthritis and ankylosing spondylitis. (linical Orthopaedics and Related Research, 72, 22-32. 